\title{
Electrochemical Impedance of Sn Nanowire Arrays
}

\author{
H. KAyA*, E. Aydogmus And D. Avcu \\ Inonu University, Science and Art Faculty, Department of Physics, Malatya, 44280, Turkey
}

\begin{abstract}
In this study, $\mathrm{Sn}$ nanowires were produced electrochemically in anodic aluminum oxide membranes. During the deposition process some parameters such as ion content, $\mathrm{pH}$, deposition time, and temperature of solution were kept constant. The scanning electron microscope results showed that the diameters of produced tin nanowires were approximately $300 \mathrm{~nm}$ and their lengths were about 8-10 $\mu \mathrm{m}$. Electrochemical impedance studies of Sn nanowire arrays were also studied by Iviumstat galvanostat/potentiostat system.
\end{abstract}

DOI: 10.12693 /APhysPolA.125.307

PACS: 81.07.Gf, 81.15.Pq, 82.80.Fk

\section{Introduction}

In today's technology, creating quite small devices is very important. In this context, the technology exhibits a transition from $\mu \mathrm{m}$ size to nano size. With the continued demand for miniaturization of electronic devices, nanowires with enhanced magnetic and electrical properties are needed. The most significant problems in the nanotechnology are conduction and their properties. One of the most important steps in overcoming this problem is to produce nano sized solder materials. The majority of solder materials used in electronics includes lead $(\mathrm{Pb})$. Lead based solder materials are toxic and harmful for the human health and ecological environment [1-4]. Because of that, the researchers interested in lead free solder materials (like $\mathrm{Sn}, \mathrm{SnAg}, \mathrm{SnAgCu}$, e.g.).

Electrochemical impedance spectroscopy (EIS) is a relatively new and powerful method of characterizing many of the electrical properties of materials and their interfaces with electronically conducting electrodes. It may be used to investigate the dynamics of bound or mobile charge in the bulk or interfacial regions of any kind of solid or liquid material: ionic, semiconducting, mixed electronic-ionic and even insulators (dielectrics). It can be used to investigate the electrochemical parameters like reaction rate, reaction mechanism, and surface properties of the samples.

In this work, tin (Sn) nanowires were fabricated in anodic aluminum oxide membranes by electrodeposition technique. Their melting points, surface and electrochemical impedance properties were investigated. The electrochemical impedance properties of tin nanowires have been reported first in this paper.

\section{Experimental}

Tin $(\mathrm{Sn})$ nanowires have been obtained by using template electrodeposition method. The electrodeposition

*corresponding author; e-mail: harun.kaya@inonu.edu.tr of Sn nanowires was undertaken in a three-electrode cell presented in Fig. 1. The reference electrode was an $\mathrm{Ag} / \mathrm{AgCl}$ (BAS, $3 \mathrm{M} \mathrm{NaCl}$, and $-35 \mathrm{mV}$ versus $\mathrm{SCE}$ at $25^{\circ} \mathrm{C}$ ) electrode. The working electrode was an anodic aluminum oxide membrane with a $1.13 \mathrm{~cm}^{2}$ total surface area. Before the electrodeposition, one side of the AAO templates was coated with $\mathrm{Au}$ to a thickness of $10 \mathrm{~nm}$ and stuck on carbon disc on copper plate for electrical contact [5]. A platinum electrode approximately 5 times larger than the cathode was used as an auxiliary electrode. Two different kinds of electrolytic bath were used in the experiments (Table). All solutions were prepared by dissolving reagent-grade chemicals in deionized water. The volume of the electrochemical bath was approximately $50 \mathrm{~mL}$. The electrodeposition was carried out at $25^{\circ} \mathrm{C}$ in a stirred solution and at a constant potential of $-1 \mathrm{~V}$ versus $\mathrm{Ag} / \mathrm{AgCl}$ for 180 min to produce the nanowires. The electrodeposition of $\mathrm{Sn}$ and electrochemical impedance properties was performed with an electrochemical analyzer system, an Iviumstat potentiostat/ galvanostat by superimposing an a.c. signal of $50 \mathrm{mV}$ amplitude on the d.c. potential over $100 \mathrm{kHz}$ to $10 \mathrm{mHz}$.

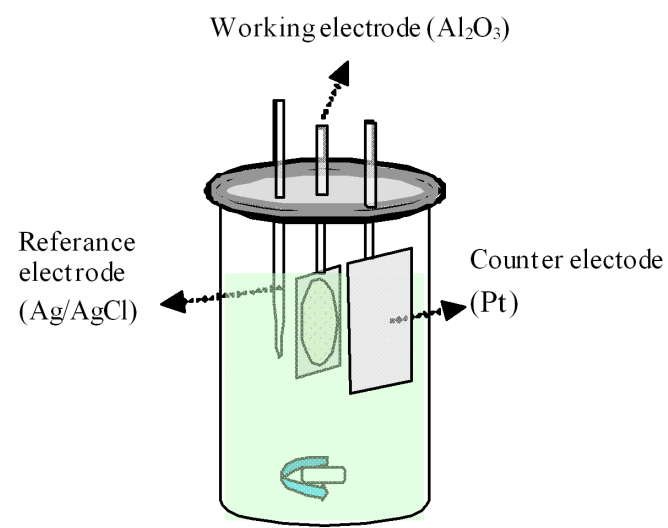

Fig. 1. A three-electrode cell.

The morphology of the nanoarrays was investigated by scanning electron microscopy (FEI NanoSEM). The quantitative chemical analyses of the alloys were per- 
TABLE

Electrolytic bath contents for production of Sn nanowires.

\begin{tabular}{c|c|c}
\hline \hline \multicolumn{2}{c|}{ Concentration } & Chemicals \\
\hline \multirow{2}{*}{ bath 1 } & $0.2 \mathrm{M}$ & $\mathrm{SnCl}_{2} \cdot 2 \mathrm{H}_{2} \mathrm{O}$ \\
& $0.6 \mathrm{M}$ & $\mathrm{C}_{6} \mathrm{H}_{17} \mathrm{~N}_{3} \mathrm{O}_{7}$ \\
\hline \multirow{4}{*}{ bath 2 } & $0.2 \mathrm{M}$ & $\mathrm{SnSO}_{4}$ \\
& $0.2 \mathrm{M}$ & $\mathrm{CH}_{4} \mathrm{~N}_{2} \mathrm{~S}$ \\
& $4 \mathrm{mM}$ & $\left(\mathrm{C}_{2} \mathrm{H}_{4} \mathrm{O}\right)_{n} \mathrm{C}_{12} \mathrm{H}_{26} \mathrm{O}$ \\
& $1 \mathrm{M}$ & $\mathrm{H}_{2} \mathrm{SO}_{4}$
\end{tabular}

formed by energy dispersive X-ray (EDX) spectroscopy. Differential scanning calorimetry (DSC) was performed in a nitrogen atmosphere with a heating rate of $10^{\circ} \mathrm{C} \min ^{-1}$, using a Shimadzu DSC-60 thermal analyzer.

\section{Results and discussion}

Electrolytic bath concentration and electrochemical parameters (like deposition potential) were optimized by our previous works $[5,6]$. Figure 2 shows the SEM images and EDX spectrum of the Sn nanowires electrodeposited in the porous alumina template, after the template was fully etched in $1 \mathrm{M} \mathrm{NaOH}$ solution. The Sn nanowires diameter is $300 \pm 10 \mathrm{~nm}$ and the length is about $10 \mu \mathrm{m}$. Sn peaks are shown in the EDX spectrum.
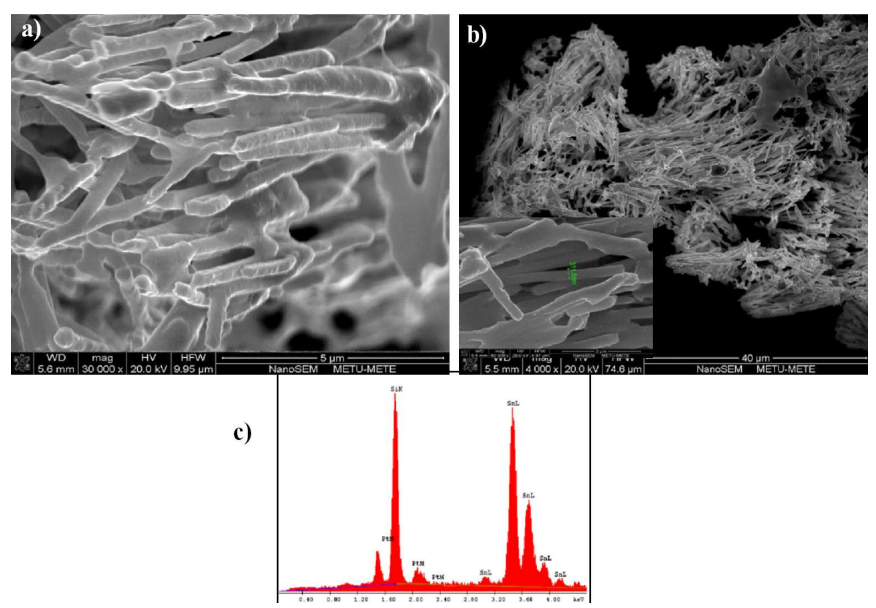

Fig. 2. SEM image of Sn nanowires: (a) bath 1, (b) bath 2, and (c) EDX spectrum of Sn nanowires.

Electrochemical impedance properties were performed for the different times while the Sn nanowires were composing. Measurements were taken after 10, 90, and 180 min of electrodeposition time. The impedance measurements results obtained from different solutions and different deposition time periods are shown in Fig. 3. For bath 1, there was no change in reaction property to high and low frequency regions. Solution resistance is constant throughout the reaction and value of the resistance is $5 \Omega$. Polarization resistance is increased with the deposition time. Kinetic controlled reaction occurred in the high and low frequency regions [7]. For bath 2, in the low frequency region, the EIS of original images at the different deposition time shows a straight line toward the imaginary $\left(Z^{\mathrm{II}}\right)$ axis, indicating that the reaction has occurred at diffusion controlled process. The real part of resistance in the high frequency region is a combination of resistance of electrolyte, natural resistance of substrate, and contact resistance at the active material/ nanowires interface. On the other hand, the combination of resistance decreased with increasing Sn nanowire electrodeposition time. Kinetic controlled reaction occurred in the high frequency region [7]. The melting point of Sn nanowires was detected in a nitrogen atmosphere with a heating rate of $10^{\circ} \mathrm{C} \mathrm{min}{ }^{-1}$, using DSC thermal analyzer (Fig. 4). The measured melting temperature was $222^{\circ} \mathrm{C}$ for both sample electrodeposited in bath 1 and 2 . It is about $10^{\circ} \mathrm{C}$ lower than the bulk melting temperature [8].
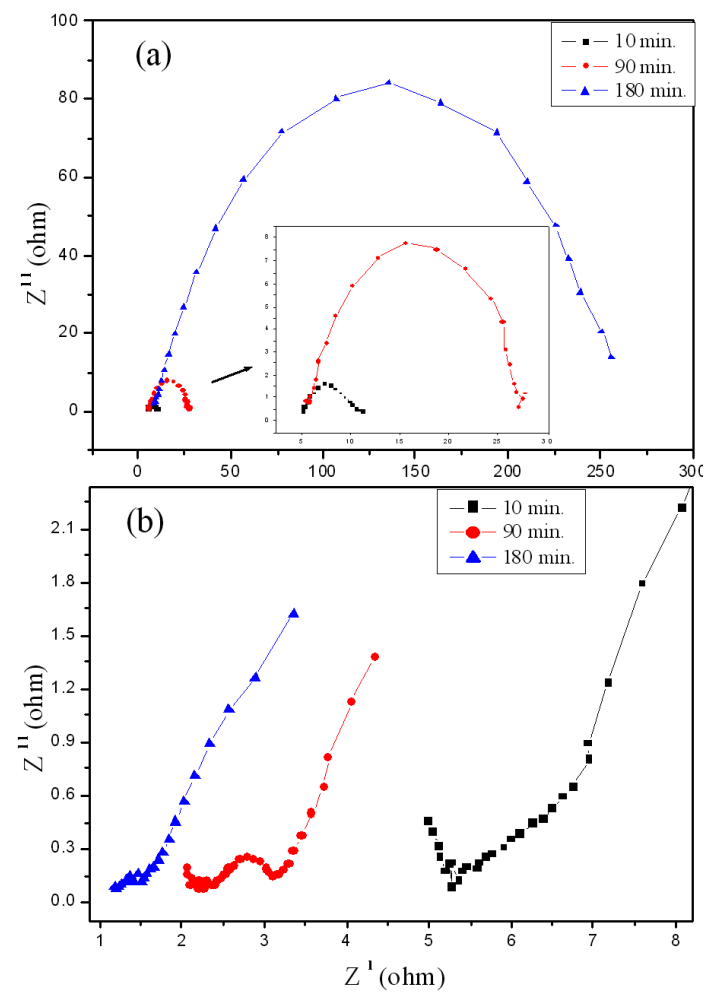

Fig. 3. Nyquist plots obtained by electrochemical impedance measurements in (a) bath 1, (b) bath 2 .

A well-defined transition is observed between the temperatures of 218 and $230^{\circ} \mathrm{C}$ for $\mathrm{Sn}$ nanowires electrodeposited in bath 1. For Sn nanowires electrodeposited in bath 2 , transition occurred between the temperatures of 203 to $235^{\circ} \mathrm{C}$. The onset melting temperatures of $\mathrm{Sn}$ nanowires obtained from bath 1 and bath 2 are 218 and $203{ }^{\circ} \mathrm{C}$. Lai et al. [9] reported the size-dependent melting temperature effect of Sn nanoparticles by calorimetry. The melting points decrease as the size of Sn particles decreases $[9,10]$. Our results agree well with Lai [9] 


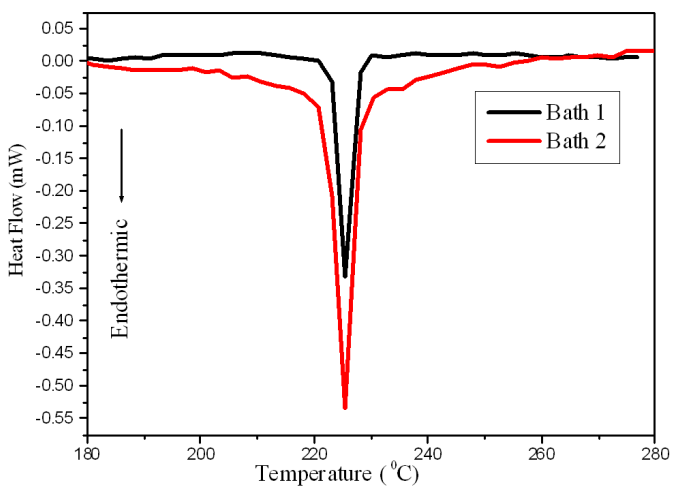

Fig. 4. The amounts of heat measured by DSC during the melting process for Sn nanowires.

and Wronski et al. [10]. Shin and friends [11] reported the size-dependence of melting points of tin nanowires. They have found that the melting point of Sn nanowire $60 \mathrm{~nm}$ in diameter is $229^{\circ} \mathrm{C}$. We got improved results than Shin's et al. [11]. So these nanowires can be applied in electronic application without altering the processing temperature.

As seen in Fig. 4, the area under the peak decreases with changing bath composition, which means that more nanocrystalline phase appears in bath 1 , and its crystallization is better than in bath $2[12,13]$. Differences between the results of DSC arise from growth mechanism of nanowires obtained in bath 1 and bath 2. Electrochemical impedance results are confirmed by the DSC measurement.

\section{Conclusions}

The Sn nanowires were produced for two different solutions in AAO templates by electrodeposition method and their impedance properties were performed. In bath 1 kinetic controlled reaction occurred but in bath 2 both kinetic and diffusion controlled reaction occurred when $\mathrm{Sn}$ nanowires were growing. The melting temperature was measured as $222^{\circ} \mathrm{C}$ for both samples electrodeposited in bath 1 and 2. Sn nanowires obtained from bath 1 crystallization are better than from bath 2 .

\section{Acknowledgments}

This work was supported by Inonu University with the project number I.U.A.F-2012/33.

\section{References}

[1] F. Rosalbino, G. Zanicchi, R. Carlini, E. Angelini, R. Maraza, Mater. Corr. 63, 492 (2012).

[2] H. Chang, H. Chen, M. Li, L. Wang, Y. Fu, J. Electron. Mater. 38, 2170 (2009).

[3] U.S. Environmental Protection Agency, Advanced Notice of Rulemaking, 1991.

[4] U.S. Environmental Protection Agency, Comprehensive Review of Lead in the Environmental under TSCA, 56 FR 22096-98, 1991.

[5] F.E. Atalay, H. Kaya, V. Yagmur, S. Tari, S. Atalay, D. Avsar, Appl. Surf. Sci. 256, 2414 (2010).

[6] F. Atalay, D. Avsar, H. Kaya, V. Yagmur, S. Atalay, T. Seçkin, J. Nanomater. 2011, ID 919853 (2011).

[7] Z.P. Chen, J.H. Jiang, G.L. Shen, R.Q. Yu, Anal. Chim. Acta 553, 190 (2005).

[8] B.H. Billings, D.E. Gray, American Institute of Physics Handbook, 3rd ed., McGraw-Hill, New York 1972, p. 4.

[9] S.L. Lai, J.Y. Guo, V. Petrova, G. Ramanath, L.H. Allen, Phys. Rev. Lett. 77, 99 (1996).

[10] C.R.M. Wronski, Br. J. Appl. Phys. 18, 1731 (1967).

[11] H.S. Shin, J. Yu, J.Y. Song, Appl. Phys. Lett. 91 , 173106 (2007).

[12] D.R. Salinas, S.G. Garcia, R. Di Santo, F.F. Marzo, J.B. Bessone, A.R. Pierna, Latin Am. Appl. Res. 33, 289 (2003)

[13] M.E. Brown, Introduction to Thermal Analysis: Techniques and Applications, Springer-Verlag, New York 2001 